Article

\title{
Structure and Properties of Poly(ethylene terephthalate) Fiber Webs Prepared via Laser-Electrospinning and Subsequent Annealing Processes
}

\author{
Tomoki Tokuda ${ }^{1}$, Ryo Tsuruda ${ }^{1}$, Takuya Hara ${ }^{1}$, Haruki Kobayashi ${ }^{1}$, Katsufumi Tanaka ${ }^{1}$, \\ Wataru Takarada $^{2}$, Takeshi Kikutani ${ }^{3}$, Juan P. Hinestroza ${ }^{4} \mathbb{D}^{\text {, Joselito M. Razal }}{ }^{5}$ iD and \\ Midori Takasaki ${ }^{1, *}$
}

1 Department of Macromolecular Science and Engineering, Graduate School of Science and Technology, Kyoto Institute of Technology, Matsugasaki, Sakyo-ku, Kyoto 606-8585, Japan; tmk.edhf@gmail.com (T.T.); alterguitarist23@gmail.com (R.T.); karuata.bb.0124@gmail.com (T.H.); haruki@kit.ac.jp (H.K.);

ktanaka@kit.ac.jp (K.T.)

2 Department of Materials Science and Engineering, Tokyo Institute of Technology, 2-12-1 Ookayama, Meguro-ku, Tokyo 152-8550, Japan; takarada.w.aa@m.titech.ac.jp

3 School of Materials and Chemical Technology, Tokyo Institute of Technology, 4259-J3-142, Nagatsuta-cho, Midori-ku, Yokohama, Kanagawa 226-8503, Japan; kikutani.t.aa@m.titech.ac.jp

4 Department of Fiber Science and Apparel Design, Cornell University, 135 Human Ecology Building, Ithaca, NY 14850, USA; jh433@cornell.edu

5 Institute for Frontier Materials, Deakin University, Geelong, VIC 3216, Australia; joselito.razal@deakin.edu.au

* Correspondence: mitakas@kit.ac.jp; Tel.: +81-75-724-7792

Received: 18 November 2020; Accepted: 9 December 2020; Published: 18 December 2020

check for updates

\begin{abstract}
Melt-electrospinning is an eco-friendly method for producing ultra-fine fibers without using any solvent. We prepared webs of poly(ethylene terephthalate) (PET) through melt-electrospinning using $\mathrm{CO}_{2}$ laser irradiation for heating. The PET webs comprised ultra-fine fibers of uniform diameter (average fiber diameter $=1.66 \mu \mathrm{m}$, coefficient of variation $=19 \%$ ). The co-existence of fibers with high and low molecular orientation was confirmed through birefringence measurements. Although the level of high orientation corresponded to that of commercial highly oriented yarn, crystalline diffraction was not observed in the wide-angle X-ray diffraction (WAXD) analysis of the webs. The crystallinity of the webs was estimated using differential scanning calorimetry (DSC). The fibers with higher birefringence did not exhibit any cold crystallization peak. After annealing the web at $116^{\circ} \mathrm{C}$ for $5 \mathrm{~min}$, a further increase in the birefringence of the fibers with higher orientation was observed. The WAXD results revealed that the annealed webs showed crystalline diffraction peaks with the orientation of the c-axis along the fiber axis. In summary, the formation of fibers with a unique non-crystalline structure with extremely high orientation was confirmed.
\end{abstract}

Keywords: poly(ethylene terephthalate); melt-electrospinning; ultra-fine fibers; birefringence; crystallinity

\section{Introduction}

Non-woven fabrics have been attracting attention because of their applicability in a wide variety of end uses, such as filtration media, battery separators, packaging sheets, and medical materials. Spun bonding, melt blowing, and electrospinning processes are mainly used for manufacturing non-woven fabrics. Among these techniques, the electrospinning process, a spinning method for producing nonwovens with submicron- and nano-scale fibers, has been actively 
investigated in recent years [1-15]. The electrospinning method can be classified into two different processes: solution spinning and melt spinning. While solution-electrospinning requires a solvent, melt-electrospinning does not, and is preferable in terms of avoiding the toxicity and costs associated with solvent recovery. Studies on melt-electrospinning have examined the effects of different heating technologies, such as electric current [3-6] or carbon dioxide $\left(\mathrm{CO}_{2}\right)$ lasers [7-15].

We have demonstrated the preparation of nano- or submicron-fibers through laser-electrospinning (LES), which is a melt-electrospinning technique using $\mathrm{CO}_{2}$ laser irradiation for heating [10-15]. Uniform and ultra-fine nylon 6 and poly(L-lactide-co- $\varepsilon$-caprolactone) fibers, with an average diameter of approximately $1 \mu \mathrm{m}$ and coefficient of variation (CV) of less than $20 \%$ [10], were successfully obtained.

Poly(ethylene terephthalate) (PET) has been widely used to create fibers, films, and bottles, and has myriad other applications. Applying the monofilament winding system to the LES, we have also investigated the influences of the drawdown ratio, laser power, and applied voltage on the structure and properties of the laser electro-spun PET fibers with diameters of approximately 12-18 $\mu \mathrm{m}$ [11]. When the drawdown ratio was increased, the birefringence and boil-off shrinkage of the electro-spun PET fibers increased, while their natural draw ratio and elongation at break decreased. In addition, when either the laser power or the applied voltage was increased, the birefringence decreased, whereas the natural draw ratio and elongation at break increased.

Ogata et al. also demonstrated the preparation of PET fibers with diameters of approximately $1 \mu \mathrm{m}$ using a melt-electrospinning system equipped with a $\mathrm{CO}_{2}$-laser melting device. Rod-like PET samples with different intrinsic viscosities (IV) were supplied for the production of webs [8]. They reported that the diameter of the resultant PET fibers decreased as laser power increased, while the obtained minimum diameters were scarcely influenced by the IV. In addition, the electro-spun PET fibers did not show any crystalline orientation in the wide-angle X-ray diffraction (WAXD) measurement. Excluding the paper by Ogata [8], we could not find any other paper that discussed the preparation of PET webs via LES.

In this current research, attempts were made to prepare PET webs consisting of finer fibers through LES and subsequent annealing processes. The structure and properties of the obtained webs were evaluated. Similar analyses were performed for the as-received and annealed, unoriented amorphous PET films for comparison. To the best of our knowledge, this is the first attempt to analyze molecular orientation in PET fibers prepared by LES.

\section{Materials and Methods}

\subsection{Preparation of Fiber Webs}

\subsubsection{Materials}

PET pellets (UNITIKA Ltd., Osaka, Japan, MA-2103, intrinsic viscosity $0.68 \mathrm{dL} / \mathrm{g}$ ) were used in this study. The polymer contained a small amount of $\mathrm{TiO}_{2}$. After drying in a vacuum at $100{ }^{\circ} \mathrm{C}$ for $6 \mathrm{~h}$ and then at $120^{\circ} \mathrm{C}$ for $6 \mathrm{~h}$, the PET pellets were fed to an extrusion system, consisting of an extruder and a metering pump, and extruded from a spinneret with a single hole $1.0 \mathrm{~mm}$ in diameter at a throughput rate of $4.7 \mathrm{~g} / \mathrm{min}$ and extrusion temperature of $290^{\circ} \mathrm{C}$. The extruded filament was taken up at a velocity of $200 \mathrm{~m} / \mathrm{min}$ using a winder placed approximately $3.3 \mathrm{~m}$ below the spinneret. The prepared PET fibers [fiber diameter: $151 \pm 8 \mu \mathrm{m}(\mathrm{CV}: 5 \%)$ ] were then supplied to the LES process.

\subsubsection{Laser-Heated Electrospinning and Annealing Processes}

The LES system (NEU-010, Katotech Co., Ltd., Kyoto, Japan) with a $\mathrm{CO}_{2}$ laser light source (PIN-30R, Onizca Glass Co., Ltd., Oume, Japan) is schematically shown in Figure 1. A PET fiber of approximately $150 \mu \mathrm{m}$ in diameter prepared by the melt-spinning process was fed to the LES system from a tube nozzle at a rate of $40 \mathrm{~mm} / \mathrm{min}$ using a feed roller. The nozzle had an outer diameter of $0.91 \mathrm{~mm}$ and an inner diameter of $0.60 \mathrm{~mm}$ (20 gauge). A high voltage of $21 \pm 4 \mathrm{kV}$ was applied 
to the nozzle. The PET fiber protruding from the nozzle was heated with the irradiation of a $\mathrm{CO}_{2}$ laser (wavelength of $10.6 \mu \mathrm{m}$, power of $16 \pm 3 \mathrm{~W}$ ) and driven to the collector by the high voltage. The collector roller was positioned $80 \mathrm{~mm}$ away from the tip of the nozzle, while the laser beam axis was positioned approximately $1 \mathrm{~mm}$ away from the nozzle tip. The laser beam was converged using a cylindrical lens and cutoff with an alumina slit to an elliptically shaped beam with short and long axes of approximately 1 and $4 \mathrm{~mm}$, respectively, where the long axis was perpendicular to the direction of fiber running.

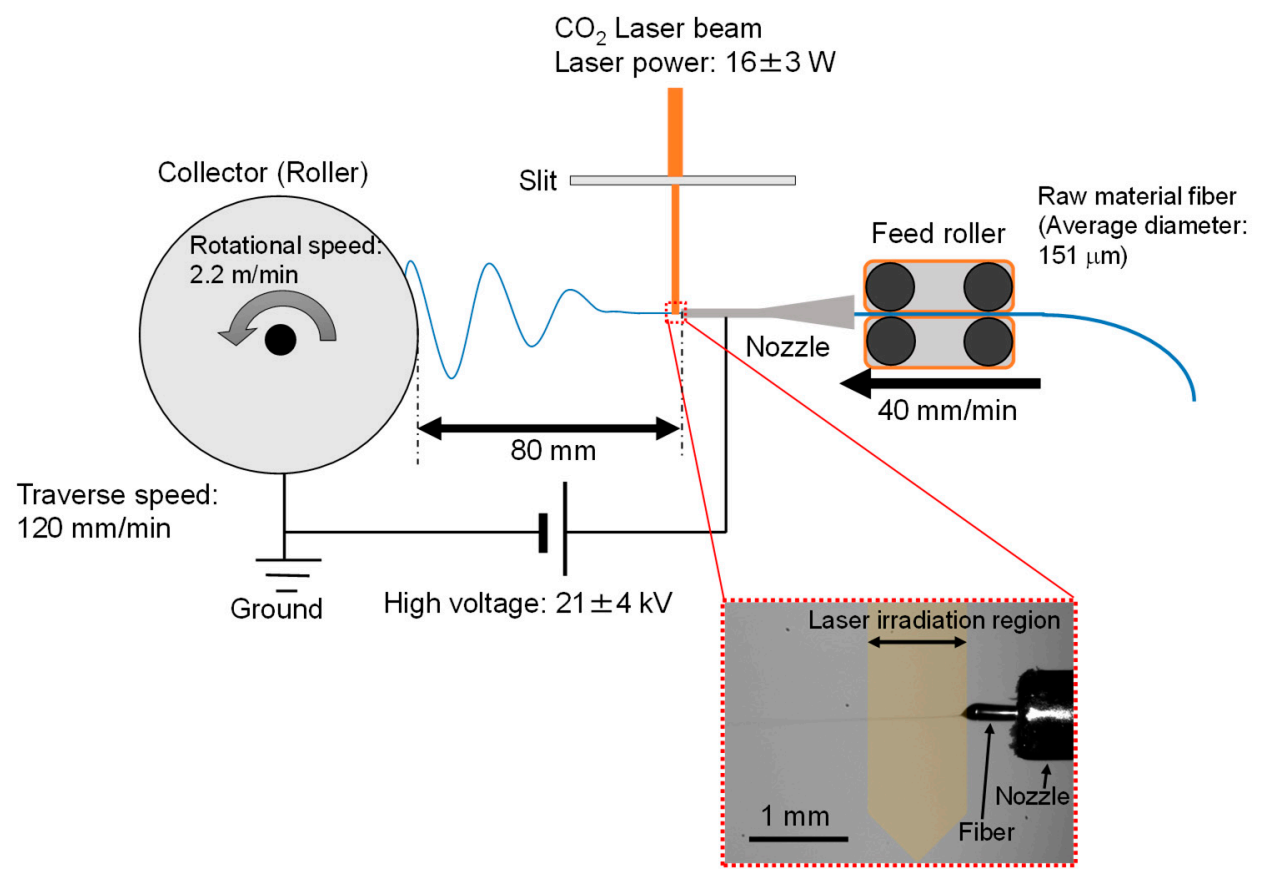

Figure 1. Schematic of the laser-electrospinning (LES) system.

The relative humidity of the atmosphere was maintained below $40 \%$ using a dry-air flow at a room temperature of approximately $25^{\circ} \mathrm{C}$. The thinning behavior of the fiber in the process was observed using a charge-coupled device (CCD) camera equipped with a telecentric lens with $2 \times$ magnification and a personal computer (Panasonic Corp., Kadoma, Japan) with the software WinROOF 2015 version 3.0.0 (MITANI Corp., Fukui, Japan). Based on the in-situ observation of the thinning behavior of the protruded fiber, the laser power and the applied voltage were adjusted so as to stabilize the spin-line near the nozzle.

A PET web was formed on the collector roller with a diameter and width of $100 \mathrm{~mm}$ at a rotational surface speed of $2.2 \mathrm{~m} / \mathrm{min}$. For the homogenization of the web thickness, linear reciprocating motion along the rotation axis was additionally applied to the collector with a traverse range and speed of $50 \mathrm{~mm}$ and $120 \mathrm{~mm} / \mathrm{min}$, respectively. After the formation of the PET web by the LES process, a web sample with the dimensions of $50 \mathrm{~mm} \times 50 \mathrm{~mm}$ with an area density of approximately $5 \mathrm{mg} / \mathrm{m}^{2}$ was placed on an amorphous PET film of the same size to prevent sag and detachment from the chuck due to the weight of the web. The thickness of the film was $246 \pm 3 \mu \mathrm{m}(\mathrm{CV}: 1 \%)$. The web and film were adhered using double-sided adhesive tape with a width of $5 \mathrm{~mm}$ around the outer rim of the film. Annealing of some samples was carried out using a dry-air oven under the fixed-size condition. The temperature was increased at a rate of approximately $3^{\circ} \mathrm{C} / \mathrm{min}$ and maintained at $116^{\circ} \mathrm{C}$ or $150{ }^{\circ} \mathrm{C}$ for $5 \mathrm{~min}$. Along with the characterization of the prepared webs, an analysis of the amorphous PET film was conducted for comparison. 


\subsection{Characterization}

\subsubsection{Scanning Electron Microscopy}

The electrospun fiber webs were coated with Au by ion sputtering (E-1010, HITACHI Co., Ltd., Tokyo, Japan) and observed using a scanning electron microscope (SEM; VE-7800, KEYENCE Co., Ltd., Osaka, Japan). For each prepared PET web, the diameters of 100 fibers were measured from the SEM images using an image analysis software (Image J version $1.52 \mathrm{v}$ ), and the average and coefficient of variation $(\mathrm{CV})$ were evaluated.

\subsubsection{Polarizing Microscopy}

The diameter and optical retardation of the raw material and electro-spun fibers were measured using a polarizing microscope (BX53-P, Olympus Co., Ltd., Tokyo, Japan) equipped with a polarizing filter and a Berek or Senarmont compensator. Birefringence, $\Delta n$, was calculated using Equation (1):

$$
\Delta n=\frac{R}{d}
$$

where $d$ is the fiber diameter and $R$ is the optical retardation.

\subsubsection{Wide-Angle X-ray Diffraction}

WAXD 2-D patterns and intensity distribution profiles of the PET web and film samples were obtained using an X-ray generator (Rigaku Co., Akishima, Japan) and a CCD detector. The WAXD analysis was performed by generating the X-ray beam at a voltage of $45 \mathrm{kV}$ and a current of $60 \mathrm{~mA}$. A Ni-filtered $\mathrm{CuK} \alpha$ beam was used.

\subsubsection{Differential Scanning Calorimetry}

For the PET web and film samples, differential scanning calorimetry (DSC) analysis was performed (Q100 MI analyzer, TA Instruments Co, Inc., New Castle, DE, USA). The samples were measured within a temperature range of $25^{\circ} \mathrm{C}$ to $30{ }^{\circ} \mathrm{C}$ at a heating rate of $10 \mathrm{~K} / \mathrm{min}$. Approximately $1 \mathrm{mg}$ and $3 \mathrm{mg}$ of the web and film samples, respectively, were weighed for measurement. Dry nitrogen was used as the purge gas at a flow rate of $50 \mathrm{~mL} / \mathrm{min}$. The DSC measurements were also conducted for the raw material fiber sample (sample mass of approximately $3 \mathrm{mg}$ ), which was cut into a powder-like form. The crystallinity of the samples was analyzed from the crystal melting endotherm, which was obtained by subtracting the exothermic heat of cold crystallization from the endothermic heat of melting. A heat of fusion of $140.1 \mathrm{~J} / \mathrm{g}$ for the $100 \%$ crystallinity was employed for the calculation of crystallinity [16].

\section{Results and Discussion}

\subsection{Fiber Diameters}

The fiber diameter distributions of the PET web samples before and after annealing at $116{ }^{\circ} \mathrm{C}$ are shown in Figure 2 along with the corresponding SEM images. The average and CV values obtained from the diameter distribution are also shown. We proved that the PET web with ultra-fine fibers and fairly uniform fiber diameter (average fiber diameter of $1.66 \mu \mathrm{m}$ and a CV of $19 \%$ ) was obtained by the LES process. There was no practical change in fiber diameter after annealing at $116^{\circ} \mathrm{C}$, indicating that the length of the fibers in the web did not change during the annealing process because of the fixation of the web size. 
(a) As-spun web

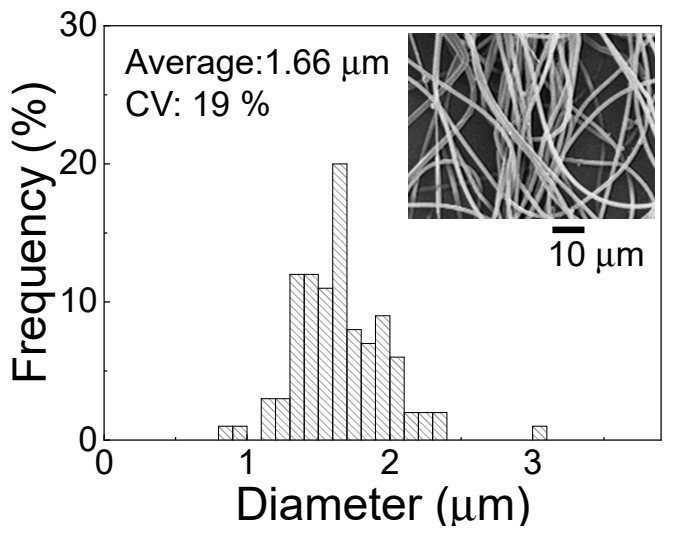

(b) Annealed web $\left(116^{\circ} \mathrm{C}\right)$

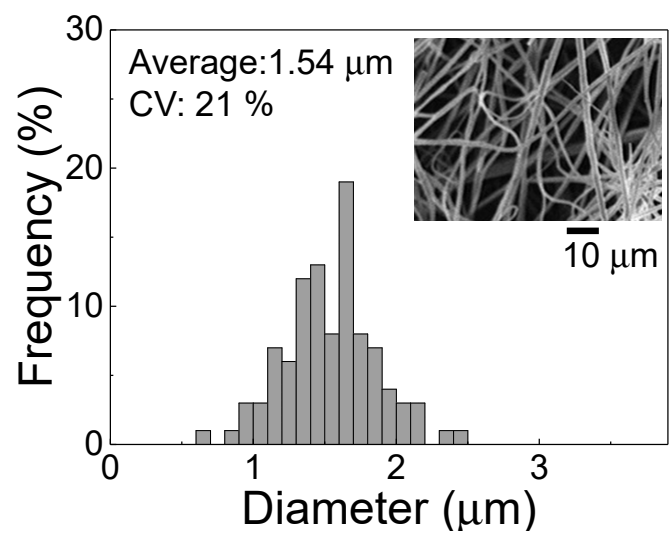

Figure 2. Fiber diameter distribution in the (a) as-spun poly(ethylene terephthalate) (PET) web and (b) web after annealing at $116{ }^{\circ} \mathrm{C}$ for $5 \mathrm{~min}$. The average value and coefficient of variation of the fiber diameters, as well as the SEM image of the web, are shown in the insets.

\subsection{Birefringence}

Micrographs of the PET fibers observed under a polarizing microscope with cross-polarization are shown in Figures 3-5. Some images were taken by inserting the Berek compensator (Olympus Co., Ltd., Tokyo, Japan) with an applied mean optical retardation of approximately 0 and $550 \mathrm{~nm}$. From these images, the diameter, retardation, and birefringence of various fibers were evaluated, as shown in Table 1.

(a) Raw material fiber

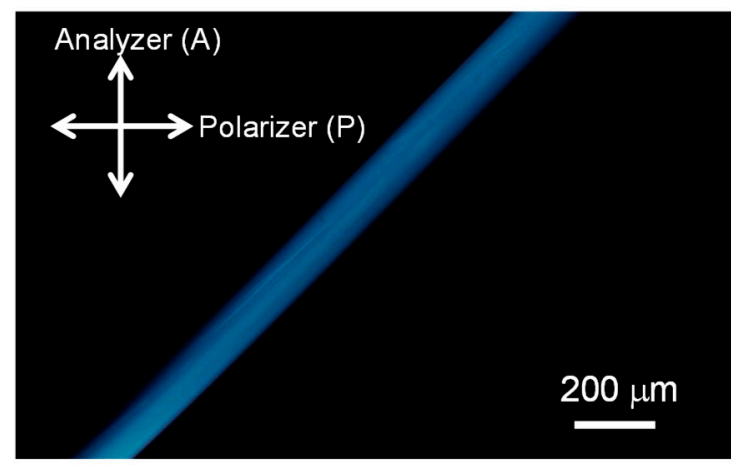

(b) As-spun web

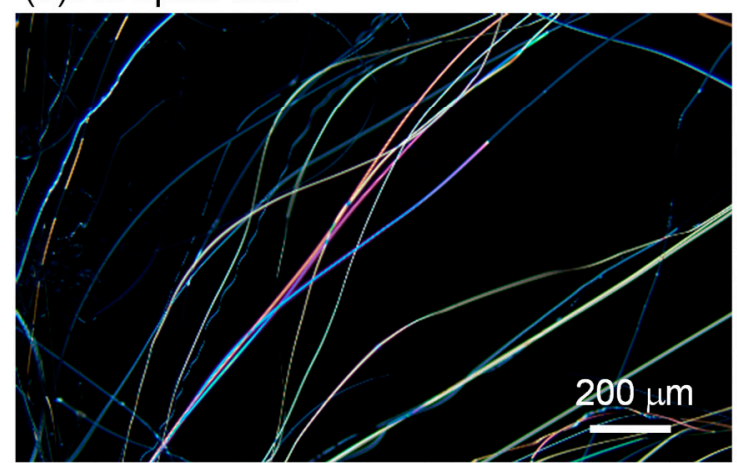

(a') Raw material fiber

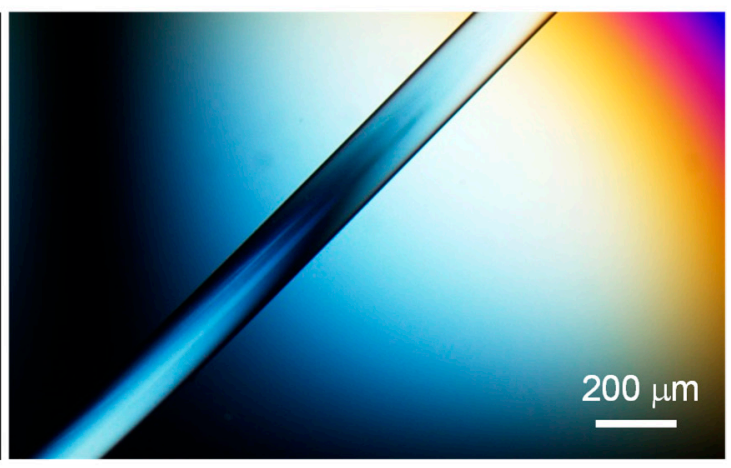

(c) Annealed web $\left(116^{\circ} \mathrm{C}\right)$

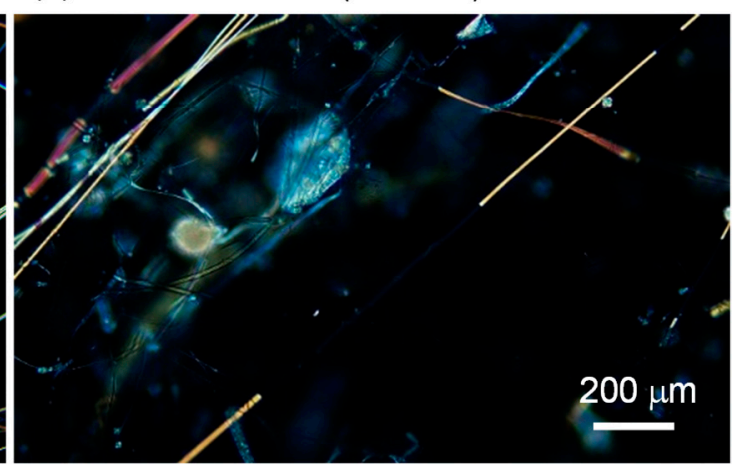

Figure 3. Micrographs observed under a polarizing microscope with cross-polarization for the (a), $\left(\mathbf{a}^{\prime}\right)$ raw material fiber (melt-spun fiber supplied for LES), (b) as-spun web, and (c) web after annealing at $116{ }^{\circ} \mathrm{C}$ for $5 \mathrm{~min}$. The directions of polarization for a polarizer and an analyzer are indicated in the figure. A Berek compensator was inserted in ( $\left.\mathbf{a}^{\prime}\right)$. 

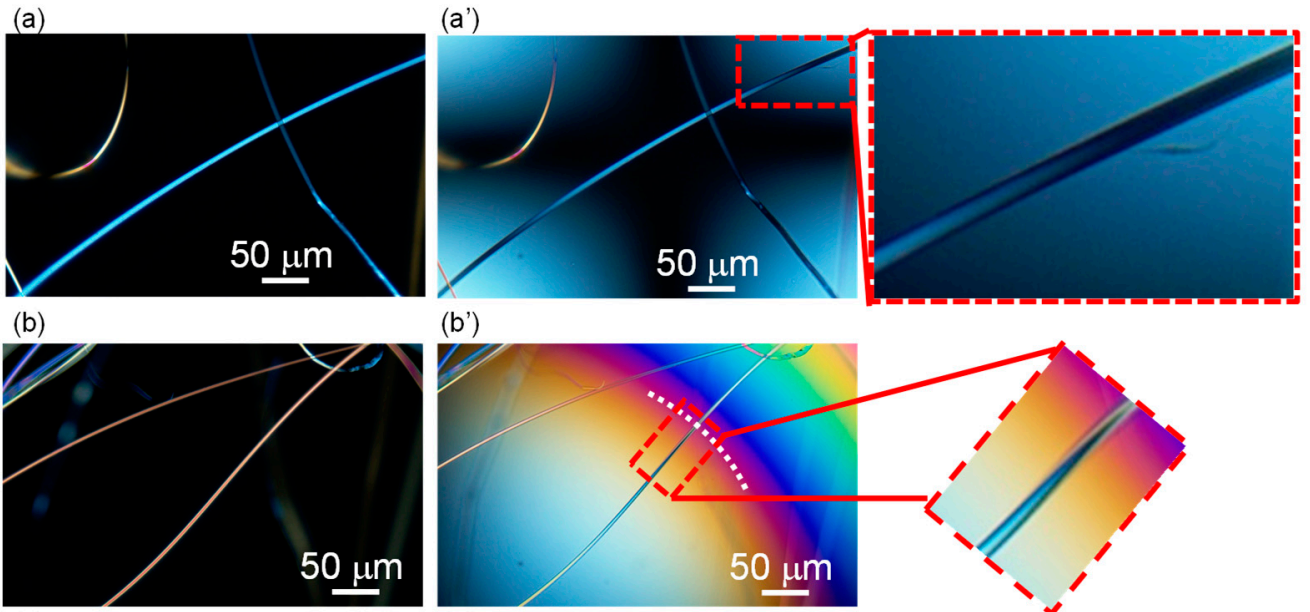

(b')
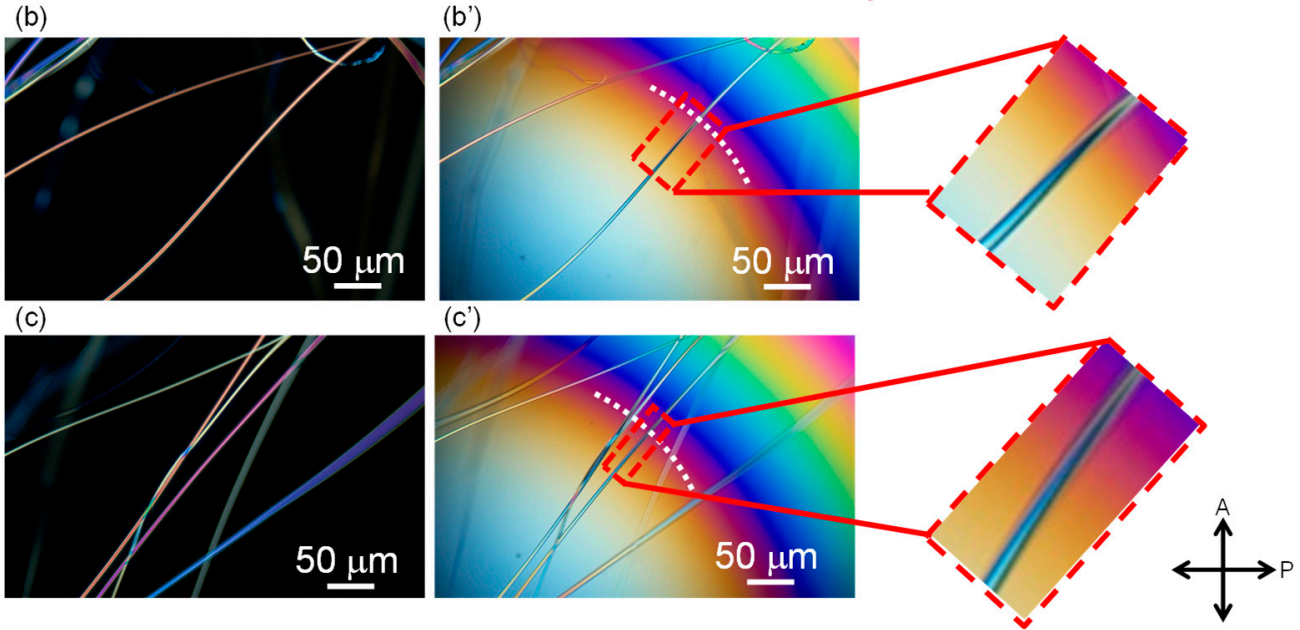

Figure 4. Typical examples of fibers in the as-spun web observed under a polarizing microscope under $(\mathbf{a}-\mathbf{c})$ cross-polarization and $\left(\mathbf{a}^{\prime}-\mathbf{c}^{\prime}\right)$ cross-polarization with the insertion of a Berek compensator. Images shown with $\left(\mathbf{a}^{\prime}\right)$ no addition of retardation at the center of the image and $\left(\mathbf{b}^{\prime}\right),\left(\mathbf{c}^{\prime}\right)$ a position with the addition of retardation of approximately $550 \mathrm{~nm}$ is indicated with a white dotted line.

(a)
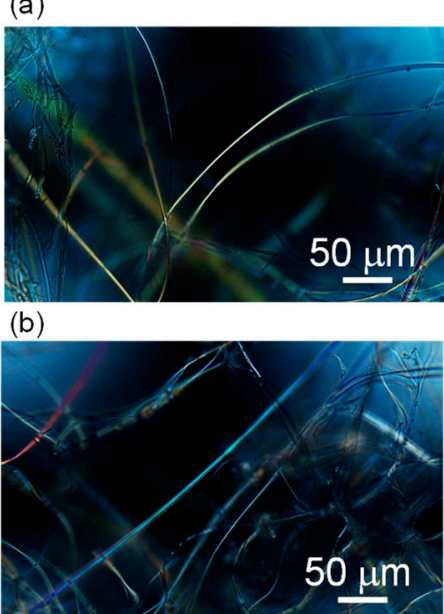

(c)

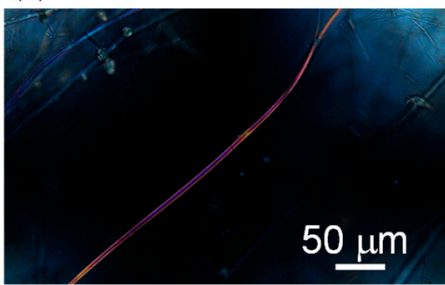

(a')

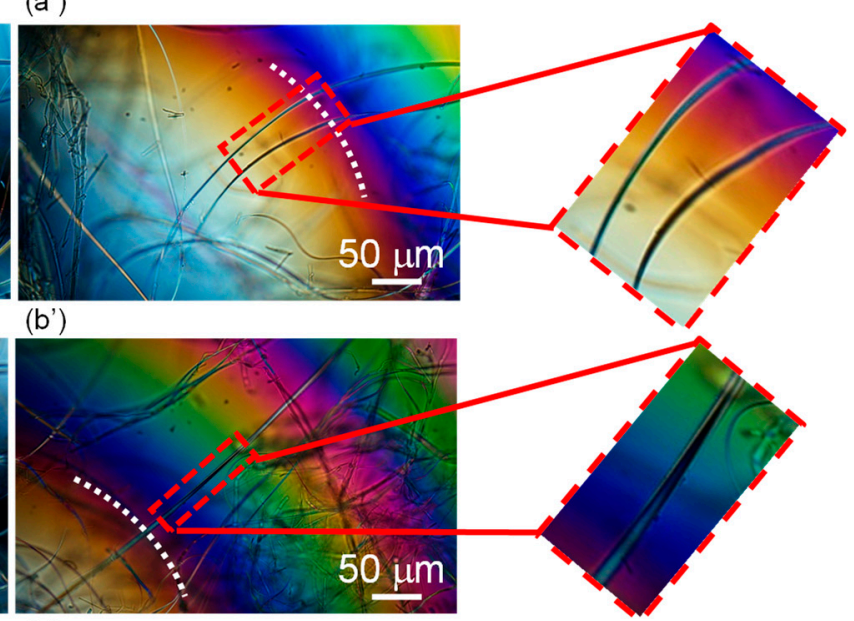

(c')

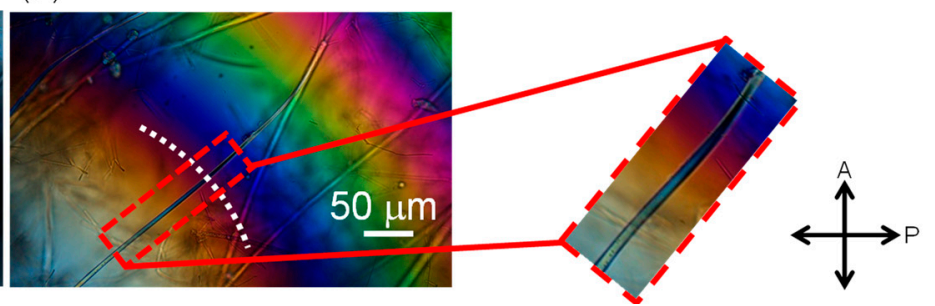

Figure 5. Typical examples of fibers in the web after annealing at $116^{\circ} \mathrm{C}$ for $5 \mathrm{~min}$, observed under a polarizing microscope with the insertion of a Berek compensator and $(\mathbf{a}-\mathbf{c})$ no addition of retardation at the center of the image and $\left(\mathbf{a}^{\prime}-\mathbf{c}^{\prime}\right)$ a position with the addition of retardation of approximately $550 \mathrm{~nm}$ is indicated with a white dotted line. 
Table 1. Retardation, $R$, diameter, $d$, and birefringence, $\Delta n$, of various fibers analyzed using a polarizing microscope.

\begin{tabular}{cccc}
\hline Sample & $\boldsymbol{R}(\mathbf{n m})$ & $\boldsymbol{d}(\boldsymbol{\mu m})$ & $\boldsymbol{\Delta} \boldsymbol{n} \times \mathbf{1 0 0 0}$ \\
\hline \multirow{2}{*}{ Raw material fiber } & 139.5 & 152.2 & 0.9 \\
& 133.4 & 59.7 & 2.2 \\
\hline \multirow{3}{*}{ As-spun web } & 438.5 & 3.6 & 121 \\
& 64.2 & 4.0 & 16.3 \\
& 310.1 & 2.9 & 106 \\
& 24.1 & 2.3 & 10.5 \\
\hline \multirow{3}{*}{ Annealed web $\left(116^{\circ} \mathrm{C}\right)$} & 336.0 & 2.2 & 150 \\
& 30.3 & 5.2 & 5.8 \\
& 558.0 & 3.7 & 203 \\
& 804.0 & 3.7 & 149 \\
& 267.0 & 5.2 & 154 \\
& & 2.2 & 119 \\
\hline
\end{tabular}

The birefringence of the raw material fibers (melt-spun fibers fed for LES) was low, as expected. On the other hand, the LES fibers in the webs showed a bimodal distribution of low and high birefringence. The diameters of the fibers were rather uniform in comparison with the wide distribution of the birefringence. Due to the limited number of measurements, a clear correlation between the birefringence and fiber diameter could not be identified.

The lower birefringence values $\left(10.5\right.$ and $\left.16.3 \times 10^{-3}\right)$ and the higher birefringence values (106 and $121 \times 10^{-3}$ ) are comparable to those of melt-spun fibers prepared at spinning speeds of $2-3 \mathrm{~km} / \mathrm{min}$ and $6-7 \mathrm{~km} / \mathrm{min}$, respectively [17]. In other words, the lower and higher birefringence values correspond to the degrees of orientation for undrawn yarn (UDY) and highly oriented yarn (HOY), respectively. After annealing the web at $116^{\circ} \mathrm{C}$, the fibers with high and low birefringence still co-existed, and the high birefringence part showed a significant increase in birefringence. This result is in accordance with the changes in birefringence of high-speed spun fibers after annealing.

\subsection{WAXD Analysis of the Web}

The WAXD patterns obtained from the through- and edge-directions of the web and film samples of PET are shown in Figure 6. In this figure, the MD, TD, and ND correspond to the winding/machine direction, transverse direction, and normal direction, respectively. The WAXD intensity profiles of the web and film samples obtained by averaging the intensity along the azimuthal direction from $0^{\circ}$ to $180^{\circ}$ are shown in Figure 7 . The intensity peaks at approximately $2 \theta=17^{\circ}, 23^{\circ}$, and $26^{\circ}$ correspond to the $(0 \overline{1} 1) /(010),(\overline{1} 10)$, and (100) reflections, respectively [18]. The appearance of only an amorphous halo was confirmed for all the samples (as-received film, raw material fiber for LES, and as-spun web) before annealing. After annealing at $116^{\circ} \mathrm{C}$ for $5 \mathrm{~min}$, the film samples did not exhibit crystalline reflections, whereas distinct crystalline reflections were observed for the annealed web samples. At an annealing temperature of $150{ }^{\circ} \mathrm{C}$, the appearance of crystalline reflections was confirmed for both the film and fiber samples.

For the web sample annealed at $116^{\circ} \mathrm{C}$, intensity profiles at azimuthal angles of $0^{\circ}$ and $90^{\circ}$ were prepared from the results of the through- and edge-direction WAXD measurements. As can be seen in Figure 8, the crystalline peak intensities were slightly stronger at $90^{\circ}$ than at $0^{\circ}$ for the edge-view measurement, although no clear difference was found for the through-view measurement. This result suggests the existence of a certain degree of c-axis orientation of the crystals in the web fibers, where the fibers were aligned parallel to the web surface. 


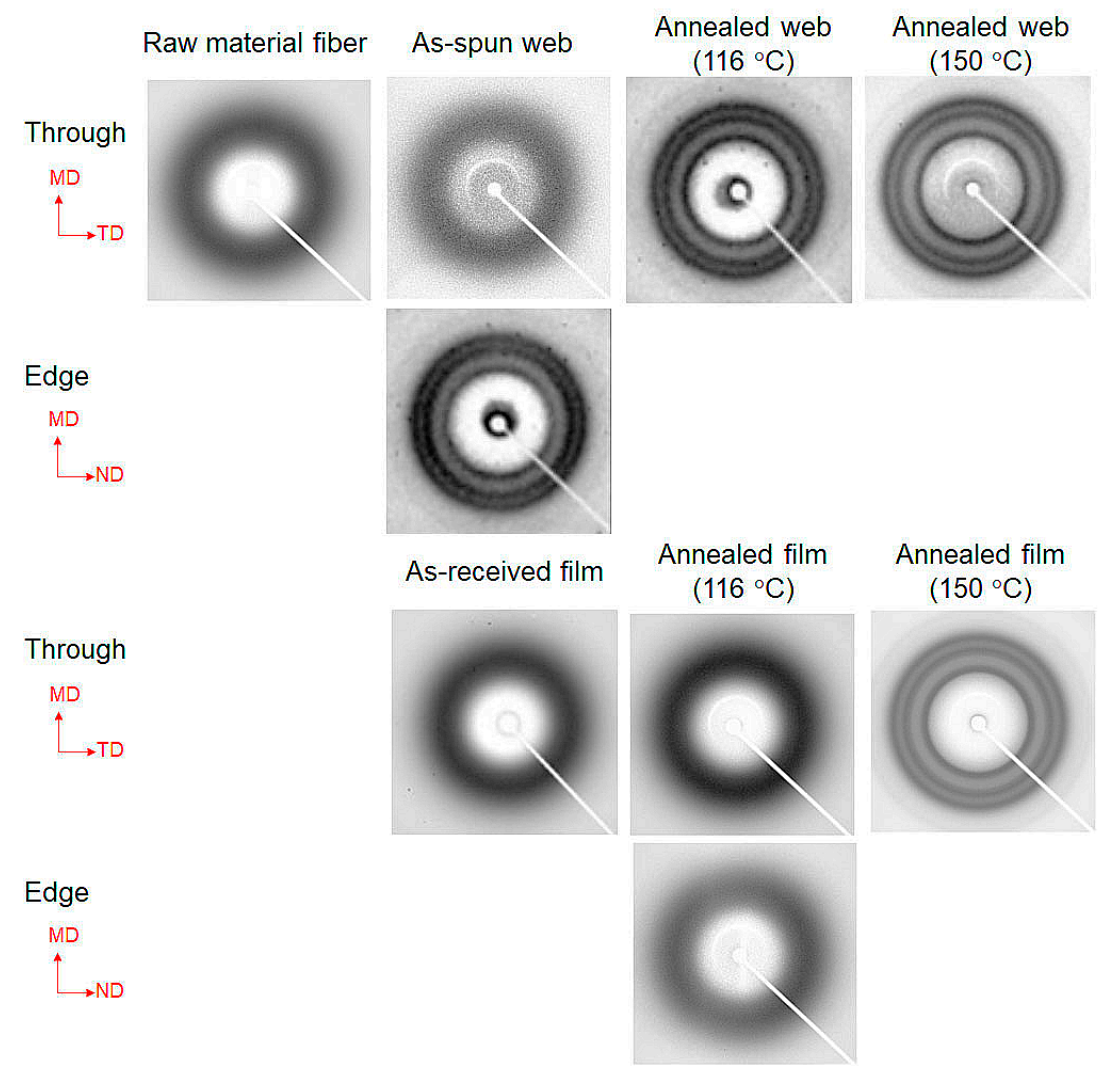

Figure 6. Wide-angle X-ray diffraction (WAXD) patterns of the web and film samples of PET obtained from the through- and edge-direction. The machine direction (MD), transverse direction (TD), and normal direction (ND) are indicated in the figure.

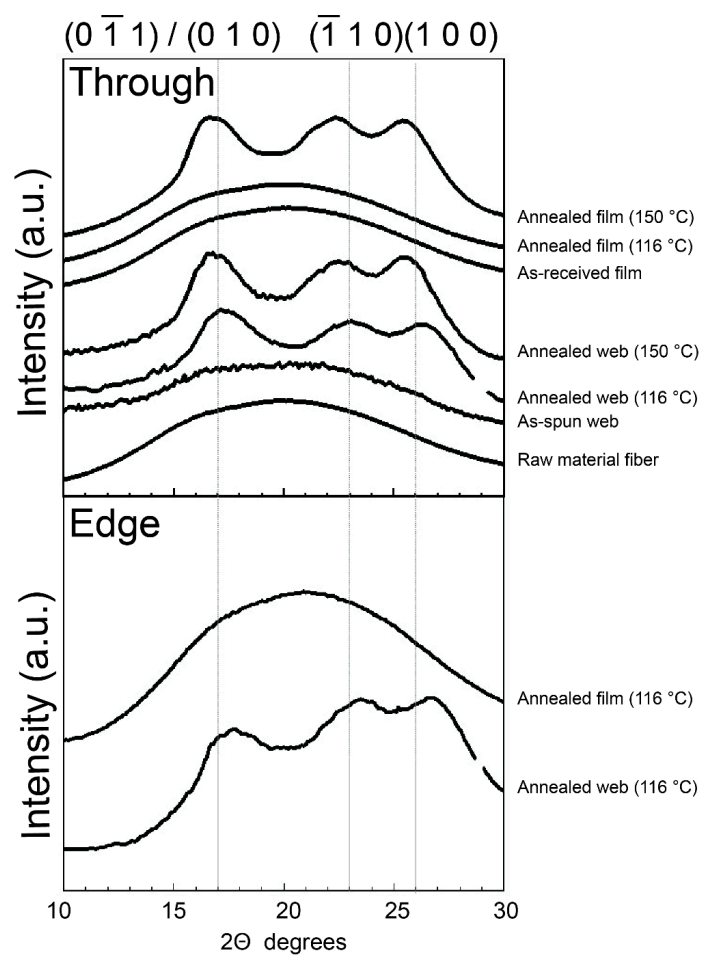

Figure 7. WAXD intensity profiles of the web and film samples obtained by averaging the intensities along the azimuthal direction from 0 to $180^{\circ}$. 


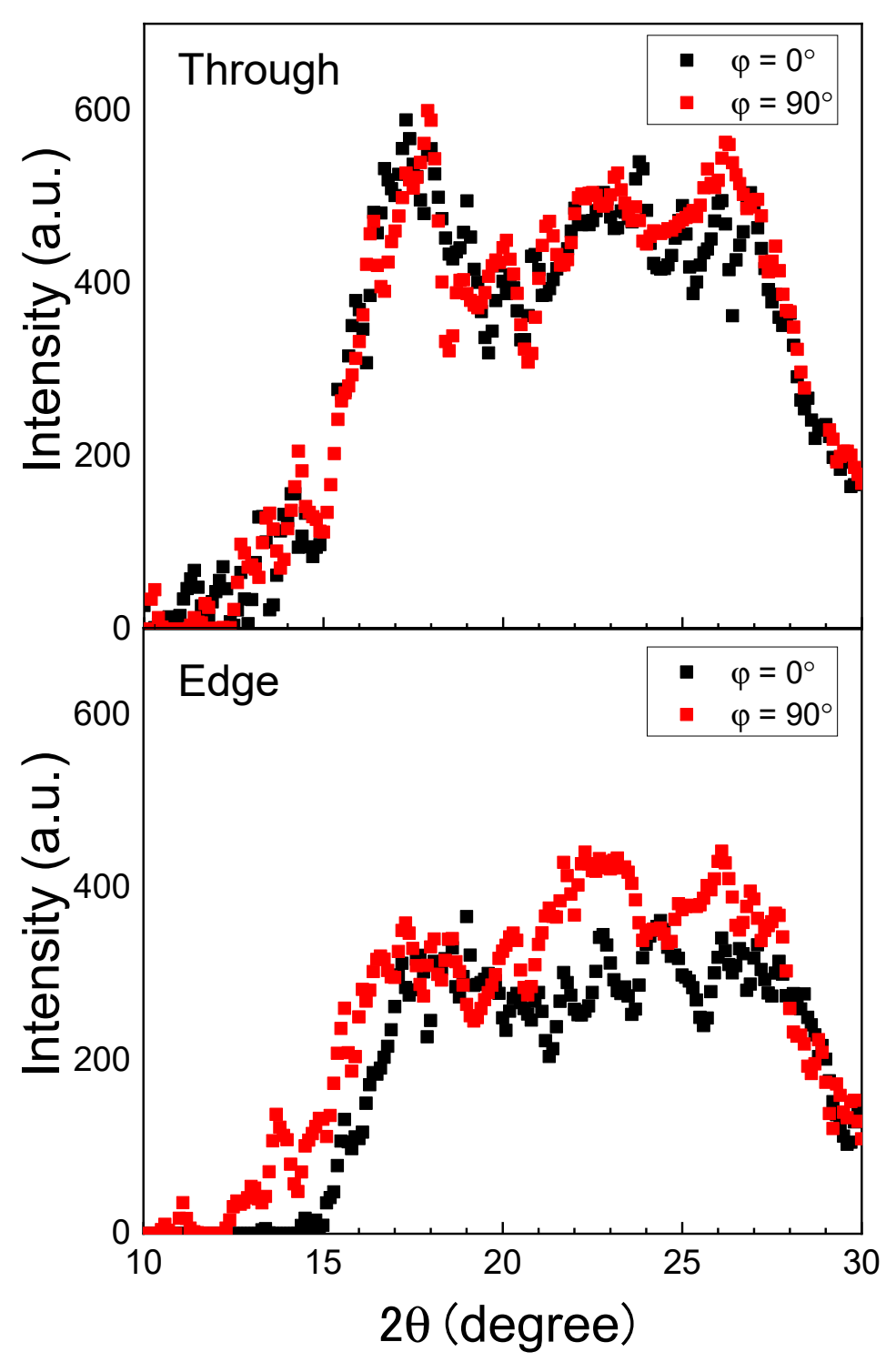

Figure 8. WAXD intensity profiles at the azimuthal angles, $\varphi$, of $0^{\circ}$ and $90^{\circ}$ for the web sample annealed at $116^{\circ} \mathrm{C}$.

\subsection{DSC Analysis}

The DSC thermograms of the web and film samples are shown in Figure 9. The crystallinity obtained from Figure 9 is shown in Figure 10. Glass transition was clearly observed at approximately $77^{\circ} \mathrm{C}$ for the as-received film and the raw material fiber, whereas that of the as-spun web was obscure. After annealing at $150{ }^{\circ} \mathrm{C}$, glass transition could not be observed both for the web and film samples. On the contrary, after annealing at $116{ }^{\circ} \mathrm{C}$, the film sample still showed a distinct glass transition, which was not observed for the web sample. In addition, an exothermic peak of cold crystallization for the as-received film and raw material fiber appeared at approximately $131{ }^{\circ} \mathrm{C}$ and $138^{\circ} \mathrm{C}$, respectively, whereas that of the as-spun web became broad and appeared at a lower temperature of approximately $118^{\circ} \mathrm{C}$, indicating the existence of fibers with a certain degree of molecular orientation. The broad cold crystallization peak may suggest the existence of an orientation distribution of the fibers with relatively low birefringence. After annealing at $116^{\circ} \mathrm{C}$, the web showed only a slight trace of the cold crystallization peak, whereas the film annealed at $116^{\circ} \mathrm{C}$ showed a distinct cold crystallization peak at approximately $130^{\circ} \mathrm{C}$. When the annealing temperature was raised to $150^{\circ} \mathrm{C}$, the cold crystallization peak disappeared completely for both the web and film samples. 


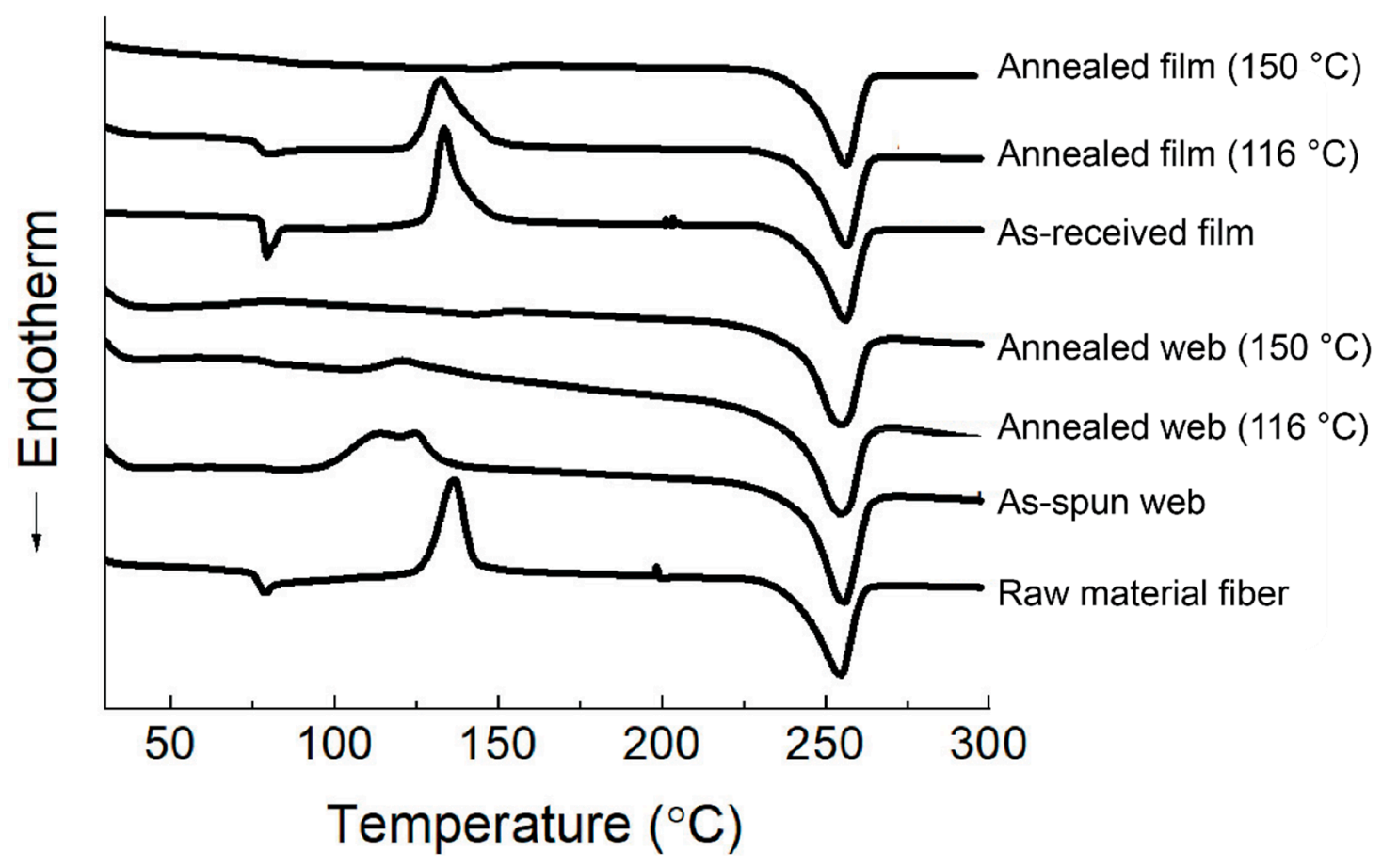

Figure 9. Differential scanning calorimetry (DSC) thermograms of the web and film samples.

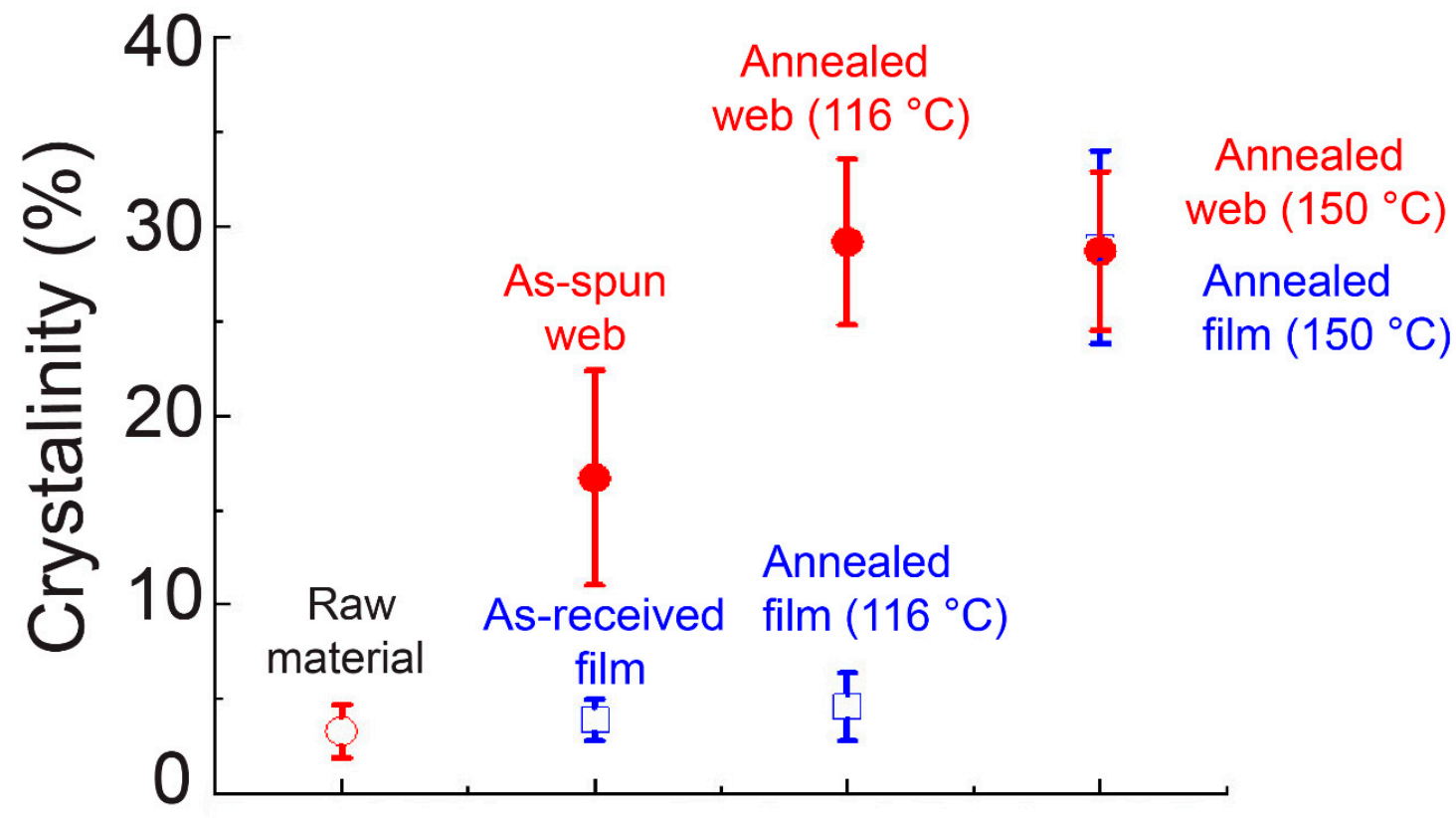

Figure 10. Crystallinity analyzed from DSC thermograms of web and film samples.

These results suggest that the annealing period of $5 \mathrm{~min}$ at $116{ }^{\circ} \mathrm{C}$ was not sufficient for the crystallization of the film with virtually no orientation, while the web sample could crystallize under these conditions because a certain degree of orientation was imposed during LES. Therefore, after annealing at $116{ }^{\circ} \mathrm{C}$, the crystallinity of the film was approximately $5 \%$, while that of the web samples was approximately $29 \%$, as shown in Figure 10 . After annealing at $150{ }^{\circ} \mathrm{C}$, both the web and film samples showed a crystallinity of approximately $29 \%$.

Although no clear diffraction peak was confirmed in the WAXD results, the crystallinity of the as-spun web sample calculated from the DSC thermogram was approximately $17 \%$, which was higher than those of the as-received film and the raw material fiber for LES ( $3 \%)$. The cold crystallization 
temperature of the as-spun web corresponded to that of the high-speed spun fibers prepared at the take-up velocity of $2-3 \mathrm{~km} / \mathrm{min}$. On the other hand, the crystallinity of the as-spun web analyzed from the DSC thermogram corresponded to that of the high-speed spun fibers prepared at the take-up velocity of 3-4 km/min [17]. The discrepancy regarding the relationship between the cold crystallization temperature and crystallinity from the DSC measurements for the LES web and the high-speed spun fibers can be explained as follows. The birefringence measurements of the fibers in the web confirmed the co-existence of fibers with low and high birefringence, as shown in Table 1. It can be speculated that the crystallinity higher than that expected from the cold crystallization temperature was obtained because of the presence of highly oriented fibers, which did not show any cold crystallization peak. It should be noted that such high-birefringence fibers did not exhibit a crystalline peak in the WAXD analysis, as shown in Figure 6.

\section{Conclusions}

PET fiber webs were prepared through laser-heated electrospinning (LES) and subsequent annealing processes. Through the analyses of the structure and properties of the obtained webs, it was proved that the PET web with ultra-fine fibers of fairly uniform fiber diameter (average fiber diameter of $1.66 \mu \mathrm{m}$ and its CV of $19 \%$ ) was obtained by the LES process. Birefringence of the LES fibers in the web showed a bimodal distribution of low and high values. After the annealing of the web at $116{ }^{\circ} \mathrm{C}$ for $5 \mathrm{~min}$, the fibers with high and low birefringence still co-existed, where the high birefringence part showed a significant increase in birefringence. In the wide-angle X-ray diffraction (WAXD) analysis, the appearance of only an amorphous halo was confirmed for the as-spun web sample before annealing, even though the existence of the fibers of high birefringence was confirmed. After the annealing of the web samples at $116^{\circ} \mathrm{C}$ or $150^{\circ} \mathrm{C}$ for $5 \mathrm{~min}$, distinct crystalline reflections were observed. In terms of the crystallinity of the as-spun web samples, although crystalline diffraction peaks were not observed in the WAXD measurements, the crystallinity estimated from the DSC thermogram showed a relatively high value of about $17 \%$. There was a discrepancy between the results for LES web and high-speed spun fibers if the relationship between the cold crystallization temperature and the crystallinity from DSC was considered, in that higher crystallinity was observed for the web in comparison with its relatively low cold crystallization temperature. The presence of highly oriented fibers, which might not show any cold crystallization peak, was speculated to be the origin of this discrepancy. After annealing at $116^{\circ} \mathrm{C}$ or $150{ }^{\circ} \mathrm{C}$, the crystallinity of the web samples reached about $29 \%$.

Author Contributions: Conceptualization, W.T., T.K. and M.T.; methodology, W.T., T.K. and M.T.; investigation, T.T., R.T. and T.H.; resources, W.T., T.K. and M.T.; data curation, T.T., R.T., T.H. and M.T.; writing-original draft preparation, T.K. and M.T.; results discussions, review and editing, H.K., K.T., W.T., T.K., J.P.H., J.M.R. and M.T.; visualization, T.T., R.T., T.H. and M.T.; supervision, T.K. and M.T.; project administration, T.K. and M.T.; funding acquisition, W.T., T.K. and M.T.. All authors have read and agreed to the published version of the manuscript.

Funding: This work was supported by JSPS KAKENHI Grant Numbers JP18H00965 and JP18K18600.

Acknowledgments: The authors would like to express their sincere thanks to Y. Nishikawa (Kyoto Institute Technology) for his support in the SEM observation. Also, the authors would like to express their sincere thanks to A. Odake, W. Kita, S. Nambu, T. Ito, and M. Tsurudome (Kyoto Institute Technology) for their support in the polarizing microscope, WAXD, and DSC measurements.

Conflicts of Interest: The authors declare no conflict of interest.

\section{References}

1. Spivak, A.; Dzenis, Y.; Reneker, D. A model of steady state jet in the electrospinning process. Mech. Res. Commun. 2000, 27, 37-42. [CrossRef]

2. Yarin, A.L.; Koombhongse, S.; Reneker, D.H. Bending instability in electrospinning of nanofibers. J. Appl. Phys. 2001, 89, 3018-3026. [CrossRef]

3. Lyons, J.; Li, C.; Ko, F. Melt-electrospinning part I: Processing parameters and geometric properties. Polymer 2004, 45, 7597-7603. [CrossRef] 
4. Malakhov, S.N.; Khomenko, A.Y.; Belousov, S.I.; Prazdnichnyi, A.M.; Chvalun, S.N.; Shepelev, A.D.; Budyka, A.K. Method of manufacturing nonwovens by electrospinning from polymer melts. Fibre Chem. 2009, 41, 355-359. [CrossRef]

5. Zhou, H.; Green, T.B.; Joo, Y.L. The thermal effects on electrospinning of polylactic acid melts. Polymer 2006, 47, 7497-7505. [CrossRef]

6. Zhmayev, E.; Cho, D.; Joo, Y.L. Modeling of melt electrospinning for semi-crystalline polymers. Polymer 2010, 51, 274-290. [CrossRef]

7. Ogata, N.; Yamaguchi, S.; Shimada, N.; Lu, G.; Iwata, T.; Nakane, K.; Ogihara, T. Poly(lactide) nanofibers produced by a melt-electrospinning system with a laser melting device. J. Appl. Polym. Sci. 2007, 104, 1640-1645. [CrossRef]

8. Ogata, N.; Shimada, N.; Yamaguchi, S.; Nakane, K.; Ogihara, T. Melt-electrospinning of poly(ethylene terephthalate) and polyalirate. J. Appl. Polym. Sci. 2007, 105, 1127-1132. [CrossRef]

9. Tian, S.; Ogata, N.; Shimada, N.; Nakane, K.; Ogihara, T.; Yu, M. Melt electrospinning from poly(L-lactide) rods coated with poly(ethylene-co-vinyl alcohol). J. Appl. Polym. Sci. 2009, 113, 1282-1288. [CrossRef]

10. Takasaki, M.; Fu, H.; Nakata, K.; Ohkoshi, Y.; Hirai, T. Ultra-Fine Fibers Produced by Laser-Electrospinning. Sen'i Gakkaishi 2008, 64, 29-31. [CrossRef]

11. Nakata, K.; Kinugawa, S.; Takasaki, M.; Ohkoshi, Y.; Gotoh, Y.; Nagura, M. The Effect of Applied Voltage and Laser Power on the Molecular Orientation of Laser-Electrospun Poly(ethylene terephthalate) Fibers. Sen'i Gakkaishi 2009, 65, 257-261. [CrossRef]

12. Takasaki, M.; Sugihara, K.; Ohkoshi, Y.; Fujii, T.; Shimizu, H.; Saito, M. Thermoplastic Polyurethane Ultrafine Fiber Web Fabricated by Laser Electrospinning. Sen'i Gakkaishi 2010, 66, 168-173. [CrossRef]

13. Takasaki, M.; Hara, K.; Ohkoshi, Y.; Fujii, T.; Shimizu, H.; Saito, M. Preparation of ultrafine polyurethane fiber web by laser-electrospinning combined with air blowing. Polym. Eng. Sci. 2013, 54, 2605-2609. [CrossRef]

14. Takasaki, M.; Kengo, M.; Ohkoshi, Y.; Hirai, T. Effects of Laser Beam Width on the Diameter and Molecular Weight of Laser-Electrospun Polylactide Fiber. Sen'i Gakkaishi 2015, 71, 232-235. [CrossRef]

15. Takasaki, M.; Nakashima, K.; Tsuruda, R.; Tokuda, T.; Tanaka, K.; Kobayashi, H. Drug Release Behavior of a Drug-Loaded Polylactide Nanofiber Web Prepared via Laser-Electrospinning. J. Macromol. Sci. Part B 2019, 58, 592-602. [CrossRef]

16. Furushima, Y.; Ishikiriyama, K.; Higashioji, T. The characteristic length of cooperative rearranging region for uniaxial drawn poly(ethylene terephthalate) films. Polymer 2013, 54, 4078-4084. [CrossRef]

17. Shimizu, J.; Okui, N.; Kikutani, T.; Toriumi, K. High Speed Melt spinning of Polyethylene terephthalate (PET); Effect of Molecular weight. Sen'iGakkaishi 1978, 34, 35-40.

18. Tomashpol'skill, Y.Y.; Markova, G.S. An electron diffraction study of the crystalline structure of polyethylene terephthalate by means of the Fourier synthesis. Polym. Sci. USSR 1964, 6, 316-324. [CrossRef]

Publisher's Note: MDPI stays neutral with regard to jurisdictional claims in published maps and institutional affiliations.

(C) 2020 by the authors. Licensee MDPI, Basel, Switzerland. This article is an open access article distributed under the terms and conditions of the Creative Commons Attribution (CC BY) license (http://creativecommons.org/licenses/by/4.0/). 